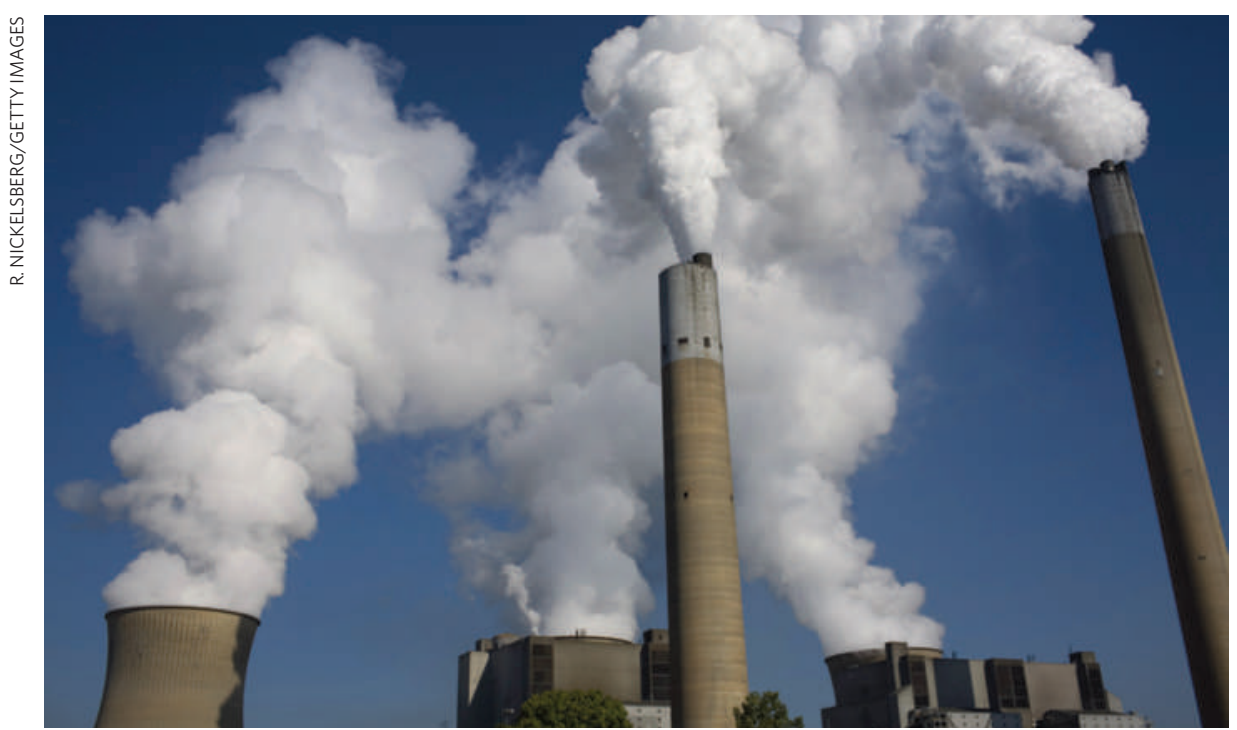

\title{
Legally binding green targets for UK
}

The United Kingdom is on track this month to become the first country to have legally binding targets for cutting greenhouse gases.

On 28 October, the British Parliament approved a bill that includes a requirement to cut carbon dioxide emissions to $80 \%$ below 1990 levels by 2050 . The bill is expected to receive royal approval this month, making it law.

"This has not been done anywhere in the world," says Jim Skea, research director of the UK Energy Research Centre in London.

Members of Parliament voted in favour of the bill after the government amended the legislation to include emissions from the aviation and shipping industries within five years. The bill sets out a broad framework within which Britain will draw up specific plans to reduce its carbon footprint.

The legally binding limits on carbon emissions will be set at five-year intervals, although it is not yet clear what penalties missing the targets would incur. And the government will have powers to set up carbon-trading schemes, to encourage firms to reduce pollution.

The bill creates an independent advisory committee on climate change made up of leading scientists and economists and led by Adair Turner, a businessman and member of the House of Lords. The group will suggest interim emissions-reduction targets leading up to 2020; recommend the levels at which the fiveyear limits should be set; and suggest actions needed by different sectors of the economy.
It will report next month to the government, which will decide by March 2009 whether to accept the suggestions.

Skea, a member of the new committee, says the bill's immediate effect will depend heavily on the interim target decided for 2020. That, he says, "will have a really big impact on the business community now".

Environmental activists praised the bill, but noted that the government is still planning to build a coal-fired power plant in Kingsnorth in southern England - a move that has met with strong protests.

Meanwhile, the European Union (EU) is pushing ahead with its own plans to modify the EU emissions-trading scheme, which is Europe's key mechanism for reducing greenhouse gases. On 24 October, be included in the scheme, starting in 2012. Aircraft produce about 3\% of Europe's greenhouse gases, and aviation emissions have increased by $87 \%$ since 1990 .

"Bringing airlines into the EU emissionstrading scheme will provide a real incentive for airlines to reduce their carbon emissions," says Ed Miliband, the UK energy and climatechange secretary.

The British Air Transport Association, an industry group, called the UK bill disappointing in focusing on national aviation limits. Roger Wiltshire, the group's secretary-general, said in a statement that the Europe-wide initiative instead represented a "sensible approach".

Natasha Gilbert 